\title{
MODEL SISTEM PENGOLAHAN DATA PENGADUAN KARYAWAN UNTUK MENGUKUR KEPUASAN PELAYANAN DALAM MENINGKATKAN KINERJA PERUSAHAAN
}

\author{
Junaidi*1 $^{1}$, Siti Euis Iyana Nurlia ${ }^{2}$, Fira Arbaimaniar Nurul ${ }^{3}$ \\ ${ }^{1}$ Program Studi Teknik Informatika Universitas Raharja, ${ }^{2,3}$ Program Studi Sistem Informasi \\ Universitas Raharja \\ Email :*1junaidi@raharja.info, ${ }^{2}$ siti.nurlia@ raharja.info, ${ }^{3}$ fira@ raharja.info
}

\begin{abstract}
Abstrak
Perusahaan yang bergerak dalam bidang industri, dewasa ini terus mengalami pertumbuhan, seiring dengan meningkatnya permintaan, hal ini tentunya diikuti dengan bertambahnya jumlah karyawan hingga mencapai puluhan ribu, agar perusahaan dapat mencapai target produksi yang ditentukan setiap harinya. Pengelolaan perusahaan dengan jumlah karyawan sebanyak ini tidaklah mudah, hal ini bias dilihat dari tingginya keluhan karyawan yang berdampak pada kinerja perusahaan. Untuk menjaga kinerja karyawan, perusahaan dituntut agar dapat mengatasi setiap pengaduan karyawan dengan cepat dantepat. Permasalahan diatas tentunya memerlukan sebuah sistem yang mampu mengukur kepuasan pelayanan perusahaan terhadap karyawan, sehingga kinerja perusahaan tetap terjaga dengan baik, selain itu sistem yang selama ini berjalan dalam bentuk form pengaduan dianggap tidak efektif dan efisien, karena mengakibatkan tingginya biaya penyiapan form dalam bentuk kertas, belum lagi kesulitan dalam rekapitulasi keluhan, ini menjadi penyebab lambatnya realisasi tindakan terhadap keluhan karyawan serta sering terjadinya kesalahan tindakan akibat ketidakakuratan laporan. Permasalahan ini dapat diatasi dengan sebuah sistem yang terkomputerisasi, sehingga diharapkan mampu menciptakan rekapitulasi dengan cepat, agar tindakan dapat dilakukan dengan tepat. Dengan menggunakan berbagai metode pegumpulan data dan analisa, meode perancangan yang meliputi diagram usecase, activity, sequen dan class diagram, untuk menghasilkan sistem yang terintegrasi sehingga bias mengukur kepuasan karyawan dan meningkatkan kinerja perusahaan.
\end{abstract}

Kata Kunci: Keluhan karyawan. Kinerja perusahaan, kepuasan karyawan.

\begin{abstract}
Companies that are engaged in industry, currently continue to experience growth, along with increasing demand, this is certainly followed by an increase in the number of employees to reach tens of thousands, so that the company can reach the specified production targets every day. Management of a company with this number of employees is not easy, this can be seen from the high number of employee complaints that have an impact on company performance. To maintain employee performance, companies are demanded to be able to deal with every employee complaint quickly and accurately. The above problems certainly require a system that is able to measure the satisfaction of company services to employees, so that the company's performance is maintained well, besides that the system that has been running in the form of complaints is considered ineffective and inefficient, because it results in high costs for paper form preparation, not to mention the difficulties in recapitulation of complaints, this is the cause of the slow realization of actions against employee complaints and frequent errors of action due to inaccurate reports. This problem can be overcome with a computerized system, so it is expected to be able to create a recapitulation quickly, so that actions can be taken appropriately. By using various data collection and analysis methods, the design method
\end{abstract}


includes usecase, activity, sequences and class diagrams, to produce an integrated system so that it can measure employee satisfaction and improve company performance.

Keywords: Employee complaints. Company performance, Employee satisfaction.

\section{PENDAHULUAN}

Studi kasus di lakukan pada PT. Victory Chingluh Indonesia yang merupakan perusahaan produksi sepatu NIKE dengan jumlah besar. Dan untuk memenuhi permintaan konsumen yang tinggi, perusahaan mempekerjakan hingga 22.000 karyawan, dari berbagai latar belakang. Dalam menangani karyawan sebanyak ini, perusahaan cukup koporatif dalam menangkap keluhan karyawan, karena bagi perusahaan, kepuasan karyawan akan berdampak pada kinerja kerja karyawan. Saat ini perusahaan telah menerapkan system formulir keluhan karyawan dimana setiap formulir disediakan di masing-masing departemen yang terletak dibeberapa bagian.

Formulir keluhan karyawan yang telah diisi, baik yang berinisial dan tidak berinisial dimasukan disetiap kotak saran disediakan, kemudian formulir ini akan di kumpulkan oleh bagian employee relation, kemudian setiap keluhan yang terkumpul akan dipelajari oleh bagian kepegawaian, untuk dibuatkan rekapitulasi keluhan berdasarkan kategori keluhan, seperti keluhan tentang kebersihan di kamar mandi, keluhan tentang fasilitas, keluhan tentang kesejahteraan, keluhan tentang kinerja pimpinan, supervasior, keluhan fasilitas parker dan sebagainya.

Adanya sistem yang terotomatisasi dapat membantu petugas dalam menyelesaikan kewajibanya dangan lebih cepat sehingga mengurangi tingkat keterlambatan yang akan mengganggu stabilitas perusahaan. Pelayanan adalah suatu urutan kegiatan yang terjadi dalam interaksi langsung antara seseorang dengan orang lain dan memenuhi kepuasan konsumen[1]. Pelayanan yang baik akan dapat menciptakan loyalitas pelanggan yang semakin erat dan konsumen tidak berpaling pada perusahaan lain[2].

Sistem adalah suatu rangkaian yang terdiri dari dua atau lebih komponen yang saling berhubungan dan saling berinteraksi satu sama lain untuk mencapai tujuan dimana sistem biasanya terbagi dalam sub sistem yang lebih kecil yang mendukung sistem yang lebih besar[3].Ketersediaan informasi yang cepat dan akurat serta didukung dengan penerapan sistem yang optimal menjadi kelebihan sendiri harus dimiliki setiap perusahaan [4].Perancangan Sistem adalah suatu kegiatan membuat desain teknis berdasarkan kegiatan pada waktu proses analisis. Perancangan disini dimaksudkan suatu proses pemahaman dan peran suatu sistem informasi berbasis komputer. [5]Data adalah fakta dari hasil pengukuran atau pengamatan. Data dapat berupa huruf-huruf, angka, simbol-simbol khusus, atau gabungan darinya. [7]

\section{METODE PENELITIAN}

Metode penelitian merupakan suatu tata cara atau kegiatan pelaksanaan penelitian rangka untuk mengumpulkan informasi atau data serta melakukan investigasi terhadap data yang telah didapatkan tersebut,yang didasari oleh asumsi-asumsi dasar, pandangan-pandangan filosofis dan ideologis, pertanyaan dan isu-isu yang dihadapi. Suatu penelitian mempunyai rancangan penelitian tertentu. Rancangan ini menggambarkan prosedur atau langkah-langkah yang harus ditempuh, waktu penelitian, sumber data dan kondisi arti untuk apa data dikumpulkan dan dengan cara bagaimana data tersebut dihimpun dan diolah untuk dianalisa dalam pembuatan laporan.

\subsection{Metode Observasi (Observasi Research)}

Pada tahapan ini penulis melakukan pengamatan langsung dari objek penelitian untuk mendapatkan data dan informasi yang akurat dan lengkap dari berbagai pihak yang terkait dan 
berhubungan dengan tema penelitian yang berhasil penulis rumuskan meliputi wawancara dan studi pustaka.

\subsection{Metode Analisis Data}

Metode analisa dilakukan dengan langkah pengamatan dan analisa terhadap sistem yangberjalan saat ini, serta menentukan rancangan use case, activity, sequence dan class diagram.

\section{PEMBAHASAN}

Diperlukan bebrapa tahapan analisa untuk dapat menggambarkan prosedur secara keseluruhan sebagai bentuk pengumpulan informasi guna mendapatkan model yang sesuai dengan kebutuhan dan mampu memberikan solusi dengan cepat secara efektif dan efisien, mulai dari tahapan pengumpulan kebutuhan, analisa dokumen, merancangan hubungan antar dokumen sampai dengan merancang model diagram database dan model rancangan sistem. Beberapa tahapan yang dimaksud sampai dengan model rancangan yang diciptakan dapat dilihat pada gambar 1,2,3,4,5.

\subsection{Use Case Diagram Prosedur Berjalan}

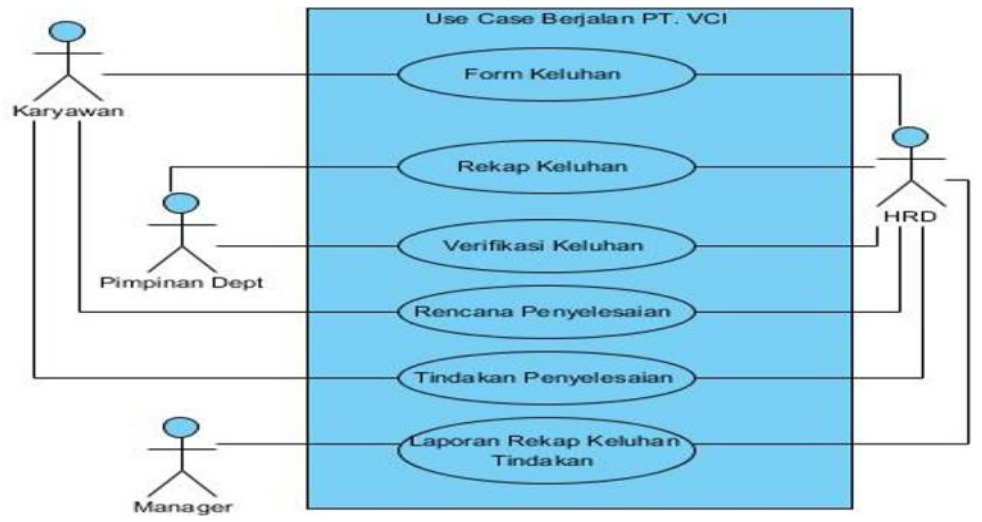

Gambar 1. Use Case Diagram

Berdasarkan gambar use case Diagram (gambar 1) yang berjalan saat ini sistem yang mencakup seluruh kegiatan pada sistem pengaduan karyawan, terdapat 4 (empat) actor yang melakukan kegiatan yaitu hrd, pimpinan departemen, manager, karyawan yang melakukan pengisian form keluhan, rekap keluhan, verifikasi keluhan, rencana penyelesaian, tindakan penyelesaian, dan melakukan laporan rekap keluhan tindakan.

Terdapat juga 6 (enam) use case yang merupakan proses yang terjadi pada sistem berjalan yaitu karyawan melakukan pengisian form keluhan dan memberikan kepada pihak hrd, setelah form keluhan di terima oleh hrd maka akan dibuatkan rekap keluhan dan verifikasi keluhan kepada pimpinan departemen, pihak hrd akan memberikan rencana penyelesaian dan tindakan penyelesaian yang akan di publikasi kepada karyawan, dan akan dibuatkan laporan rekap keluhan tindakan kepada manager. 


\subsection{Activity Diagram Prosedur Berjalan}

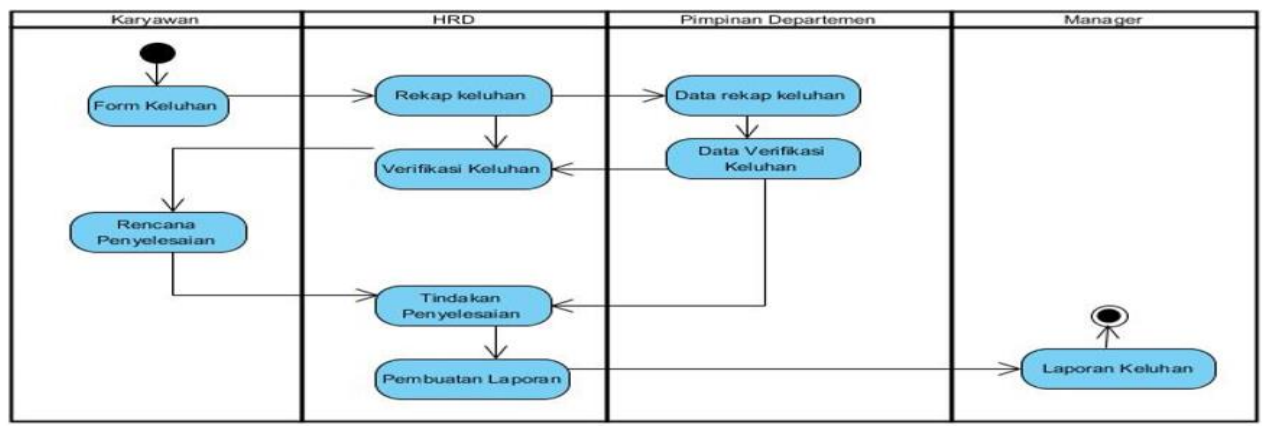

Gambar 2. Activity Diagram

Berdasarkan gambar activity diagram (gambar 2) yang berjalan saat ini sistem mencakup seluruh kegiatan penggaduan karyawan.Sistem ini melibatkan 4 (empat) actor yaitu, karyawan melakukan pengisian form keluhan dan memberikan kepada pihak hrd, setelah form keluhan di terima oleh hrd maka akan dibuatkan rekap keluhan dan verifikasi keluhan kepada pimpinan dept, pihak hrd akan memberikan rencana penyelesaian dan tindakan penyelesaian yang akan di publis kepada karyawan, dan akan dibuatkan laporan rekap keluhan tindakan kepada manager.

\subsection{Squence Diagram Prosedur Berjalan}

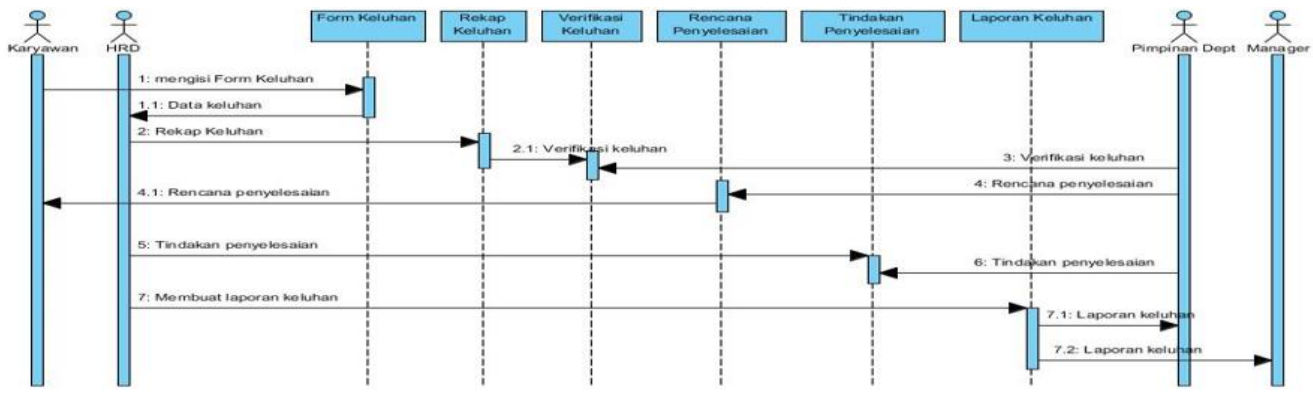

Gambar 3. Squence Diagram

Berdasarkan gambar sequence diagram (gambar 3) yang berjalan saat ini terlihat 4 (empat) actor yang melakukan kegiatan diantaranya karyawan, hrd, pimpinan dept, manager, yang akan menyelesaikan 12 message spesifikasi dari komunikasi antar objek yang memuat informasi-informasi tentang aktifitas yang terjadi, yaitu karyawan melakukan pengisian form keluhan dan memberikan kepada pihak hrd, setelah form keluhan di terima oleh hrd maka akan dibuatkan rekap keluhan dan verifikasi keluhan kepada pimpinan dept, pihak hrd akan memberikan rencana penyelesaian dan tindakan penyelesaian yang akan di publis kepada karyawan, dan akan dibuatkan laporan rekap keluhan tindakan kepada manager.

Rancangan diatas (gambar 1, 2,3) merupakan gambaran prosedur yang berjalan dimana pada tahapan ini melibatkan beberapa dokumen form keluhan tertulis yang di isi oleh setiap karyawan yang akan melakukan atau memberikan keluhan yang ada dan akan di masukkan kepada pihak hrd melalui kotak saran yang masih menggunakan manual, maka ketika hrd mentindaklanjuti akan diberikan rekap keluhan, verifikasi keluhan kepada pimpinan dept karyawan yang melapor, dan akan di berikan rencana penyelesaian dan tindakan penyelesaian, maka dibuatkan laporan rekap keluhan tindakan. 


\subsection{Class Diagram}
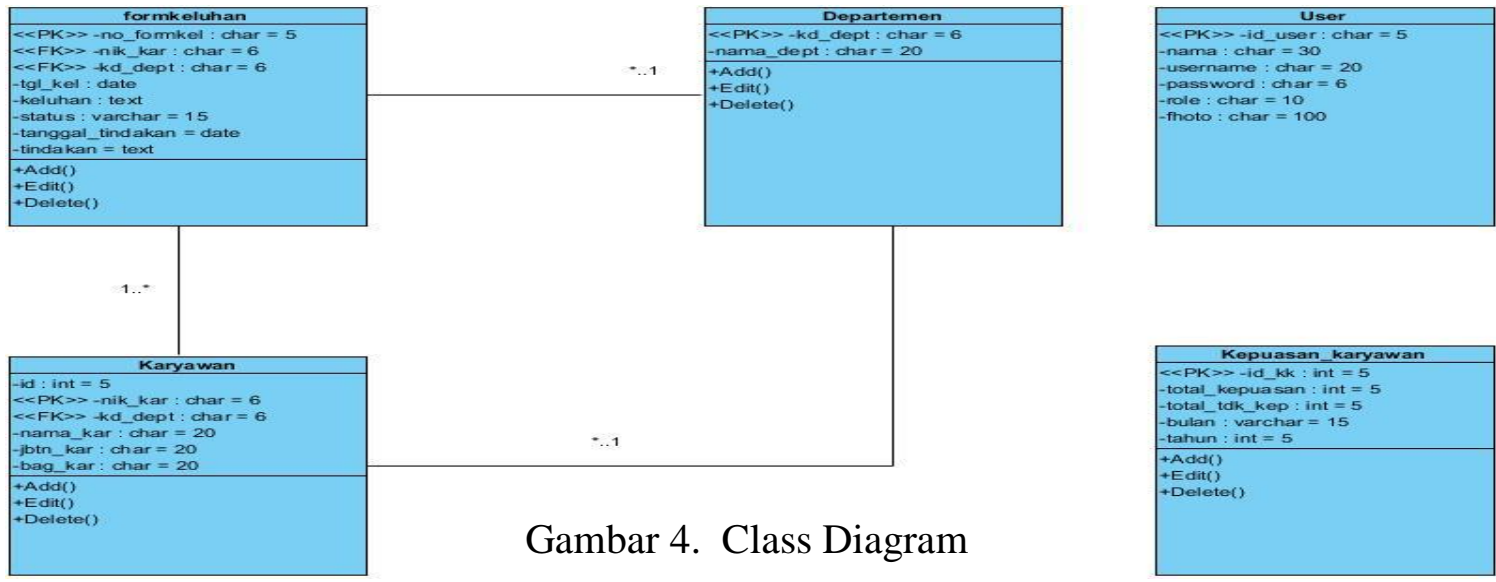

Berdasarkan gambar class diagram (gambar 4) yang berjalan saat ini sistem yang mencakup seluruh kegiatan pada system pengaduan karyawan. Terdapat 5 (lima) class yaitu karyawan, departemen, yang merupakan table master, form keluhan, rekap keluhan, kepuasan karyawan sebagai tabel transaksi, juga terdapat tabel user yang merupakan table akses untuk masuk kedalam sistem.

Berdasarkan gambar class diagram (gambar 4) diatas dapat dilihat dengan jelas bahwa tingkat hubunganform keluhan dan karyawan yaitu one to many (1:M), tingkat hubungan karyawan dan departemen yaitu one to many (1:M), ), tingkat

Hubungan departemen dan form keluhan yaitu one to many (1:M) dan terdapat table user dan kepuasan karyawan yang berdiri sendiri.

\subsection{Use Case Diag`ram Usulan}

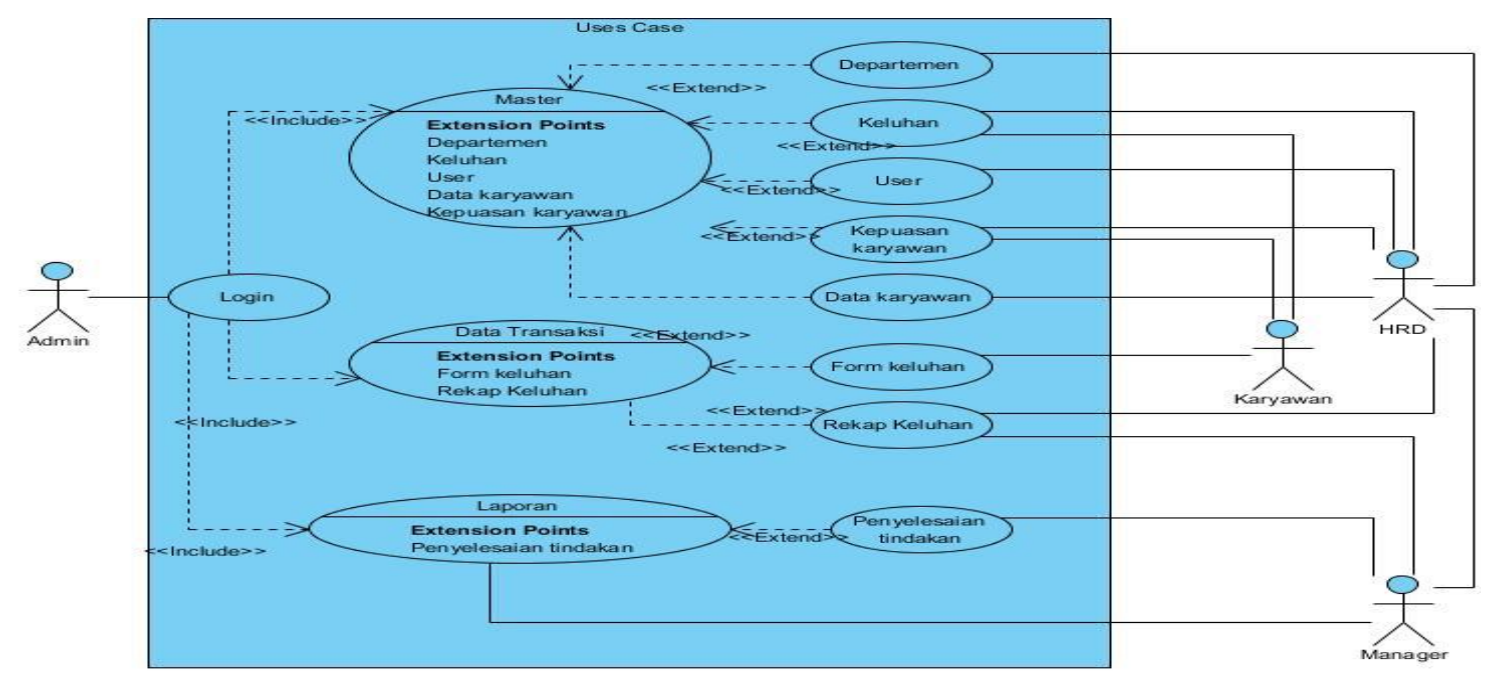

Gambar 5. Use Case Diagram

Berdasarkan gambar use case diagram usulan (gambar 5) terlihat jelas bahwa terdapat 12 (dua belas) use case yang terdiri dari 3 (tiga) use case utama yaitu master, transaksi, laporan. Use case master memiliki 5 (lima) yang terdiri dari departemen yang terhubung dengan keluhan, user, kepuasan karyawan, data karyawan. Use case transaksi memiliki 2 (dua) yang terdiri dari form keluhan, rekap keluhan.Use case laporan memiliki 1 (satu) yang terdiri dari laporan hasil penyelesaian tindakan. 
Use case diagram sebagai bentuk rancangan sistem yang akan diciptakan (gambar 5) merupakan desain model tampilan utama yang berorientasi pada kebutuhan menu aplikasi yang disiapkan, selain itu untuk kebutuhan penyimpanan informasi data agar dapat digunakan secara histori juga digambarkan dalam bentuk class diagram (gambar 4) lengkap dengan informasi field dan type data sesuai kebutuhan penyimpanan data. Serta use case login yang merupakan akses awal untuk masuk kedalam sebuah sistem berdasarkan informasi data username dan password.

\subsection{IMPLEMENTASI}

\subsubsection{Rancangan Basis Data}

Untuk dapat menggamarkan bentuk basis data secara utuh, peneliti penggunakan aplikasi microsoft access sebagai bentuk gambaran dasar, dan pada akhirnya bentuk rancangan basis data ini dapat disesuaikan menggunakan apa saja sesuai kebutuhan.

a. Tabel Master: Departemen

Primary Key : kd_dept

Foreign Key : : -

Structure Tabel : $\{$ kd_dept, nama_dept $\}$

\begin{tabular}{|c|c|c|c|c|c|c|c|c|}
\hline & $\#$ & Name & Type & Collation & Attributes & Null & Default & Extra \\
\hline$\square$ & 1 & kd_dept & char(6) & & & No & None & \\
\hline$\square$ & 2 & nama_dept & char(20) & & & Yes & NULL & \\
\hline
\end{tabular}

b. Tabel Master: Form Keluhan

Tabel 1. Struktur Deprtemen

Primary Key : no_formkel

Foreign Key : : -

Structure Tabel : \{ no_formkel, nik_kar, kd_dept, tgl_kel, keluhan, status, tanggal_tindakan, tindakan \}

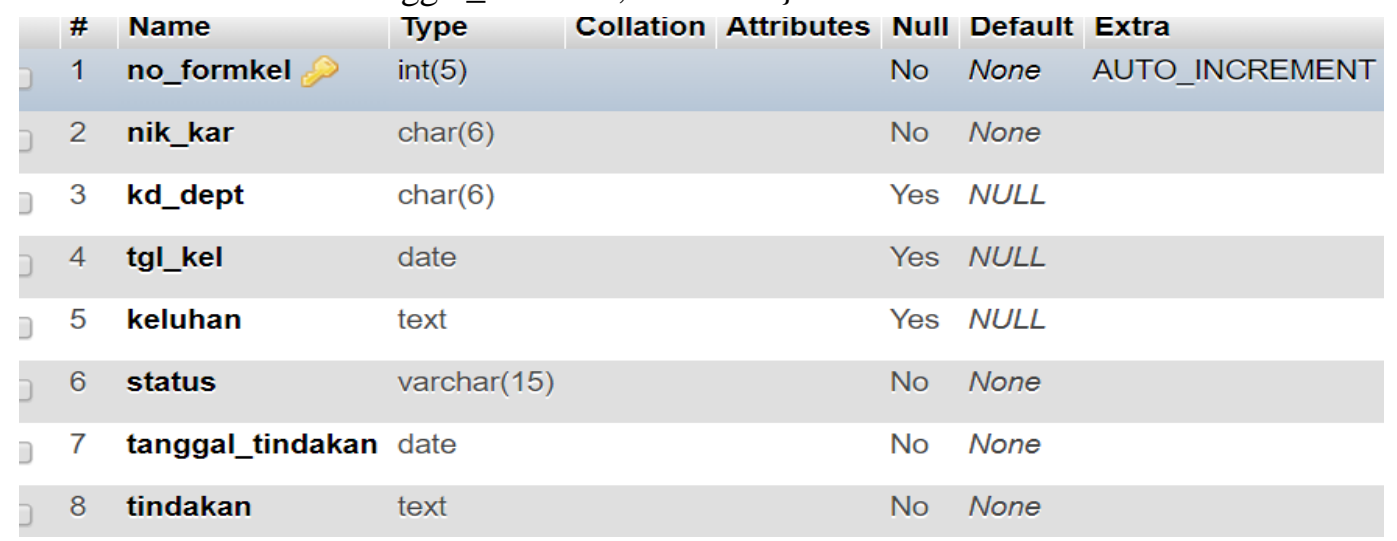

c. Tabel Master: Karyawan Tabel 2. Stuktur Form Keluhan
Primary Key : nik_kar

Foreign Key : -

Structure Tabel $\quad: \quad\{$ id, nik_kar, kd_dept, nama_kar,jbtn_kar, bag_kar $\}$

\begin{tabular}{|c|c|c|c|c|c|c|c|c|}
\hline & \# & Name & Type & Collation & Attributes & Null & Default & Extra \\
\hline$\square$ & 1 & id $\mapsto$ & $\operatorname{int}(5)$ & & & No & None & AUTO_INCREMENT \\
\hline$\square$ & 2 & nik_kar $>$ & char(6) & & & No & None & \\
\hline$\square$ & 3 & kd_dept & char(6) & & & Yes & NULL & \\
\hline$\square$ & 4 & nama_kar & char (20) & & & Yes & NULL & \\
\hline$\square$ & 5 & jbtn_kar & char $(20)$ & & & Yos & NULL & \\
\hline$\square$ & 6 & bag_kar & char (20) & & & Yos & NULL & \\
\hline
\end{tabular}

Tabel 3. Stuktur Karyawan 


\section{d. Tabel Master: KepuasanKaryawan}
Primary Key
Foreign Key
: id_kk
Structure Tabel$$
\text { :- }
$$

\begin{tabular}{|llllll} 
\# & Name & Type & Collation Attributes & Null Default Extra \\
\hline 1 & id_kk & int(5) & No & None AUTO_INCREMENT \\
\hline & total_kepuasan & int(5) & No None \\
\hline 3 & total_tidak_kepuasan $\operatorname{int}(5)$ & No None \\
\hline 4 & bulan & varchar(15) & No None \\
\hline 5 & tahun & $\operatorname{int}(5)$ & No None
\end{tabular}

\subsection{Grafik Monitoring PengaduanKaryawan}

Tabel 4. Struktur Kepuasan Karyawan

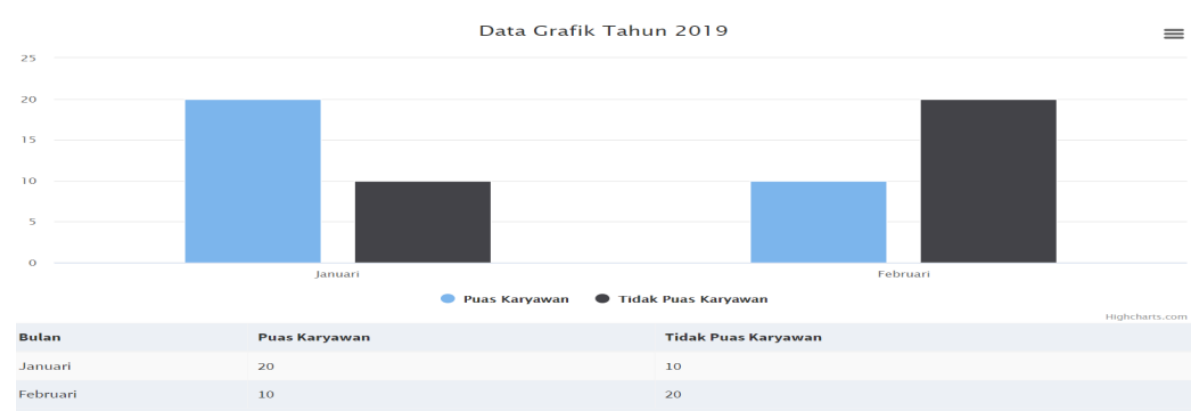

Gambar 6. Grafik Kepuasan dan Tidak Kepuasan Karyawan 2019

Grafik diatas (gambar 6) merupakan grafik Kepuasan dan Tidak Kepuasan berdasarkan waktu (tahunan). Hal ini bisa membantu manajemen dalam menunjang keputusan guna pembayaran mana yang menjadi prioritas pembayaran. Grafik diatas bisa diambil berdasarkan Datewarehouse, sebagaimana di definisikan "Doing Data Warehouse (DW) to your business or system is not only think about the trend only, but how to understand the DW knowledge itself and how to implement it" [6]. Dan bagaimana cara mengukurnya "Measures are a standard unit used to express the size, amount, or degree of something, qualities are often difficult to be measured as it needs to have some certain parameter or elements, and those parameters must be quantifiable and verifiable" [8]

\subsection{Diagram HIPO}

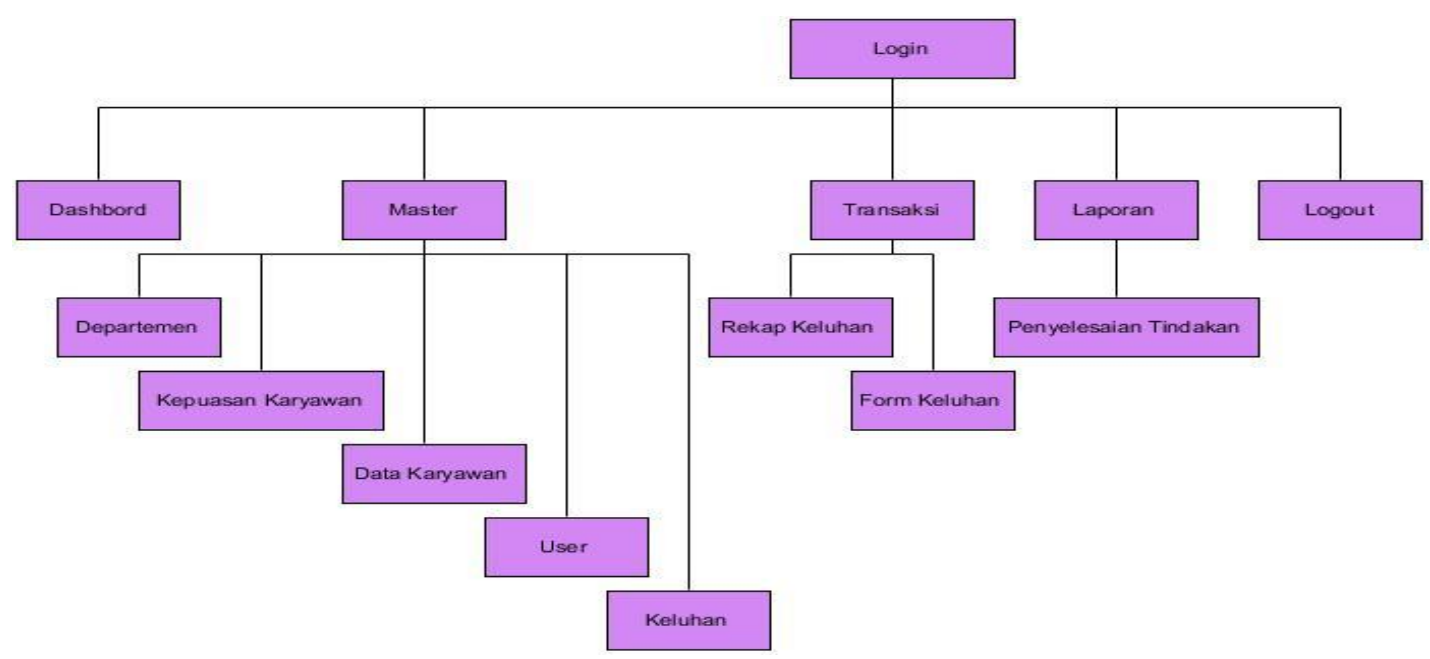

Gambar 7. Diagram HIPO 
Untuk menggambarkan stuktur menu dari sistem yang dirancang dapat digambarkan dengan diagram HIPO (Hierarchy Input Process Output).Untuk menyediakan suatu struktur guna memahami fungsi-fungsi dari program.Terlihat dari diagram HIPO diatas (gambar 7) terdapat 1 (satu) fungsi utama yaitu login (digram 0) dan 5 (lima) fungsi dibawahnya, yaitu fungsi menu dashboard (diagram 1), menu data master (diagram 2), menu data transaksi (diagram 3), menu data laporan (diagram 4) dan menu logout (diagram 5). Didalam fungsi menu data master (diagram 2) terdapat 5 (lima) fungsi sub menu yaitu menu departemen (diagram 2.1), menu kepuasankaryawan (diagram 2.2), data karyawan (diagram 2.3), menu user (diagram 2.4), dan menukeluhan(diagram 2.5). Didalam fungsi menu data transaksi (diagram 3) terdapat 2 (dua) fungsi sub menu yaitu menu rekapkeluhan (diagram 3.1), menu form keluhan(diagram 3.2). Didalam fungsi menu laporan (diagram 4) terdapat 1 (satu) fungsi sub menu yaitu menu laporanpenyelesaiantindakan (4.1).

\subsection{Rancangan Tampilan}

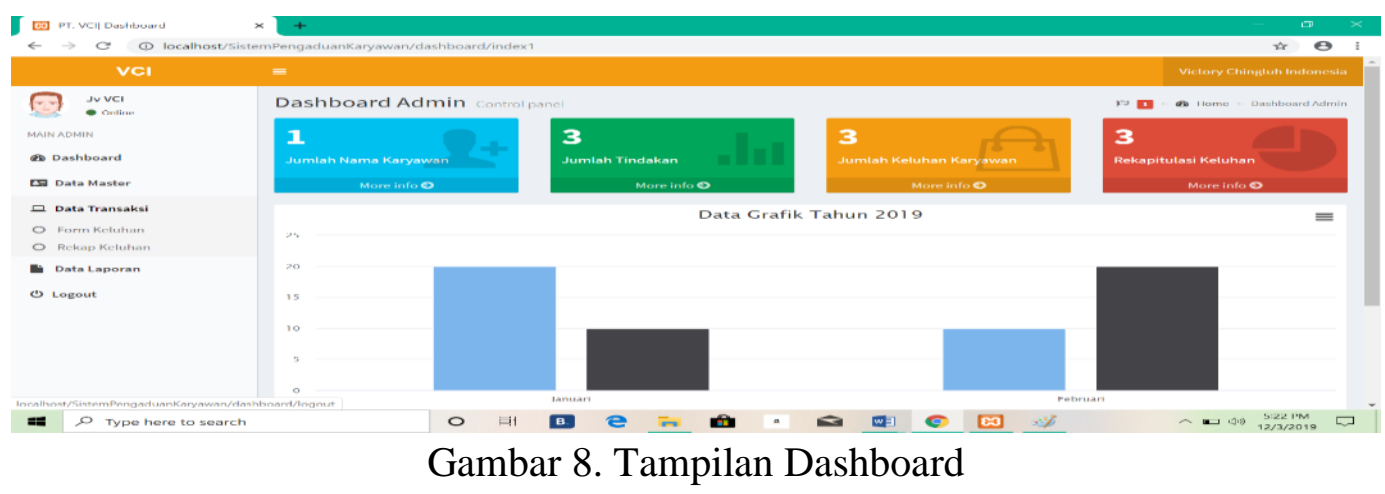

Terlihat pada tampilan layar diatas (gambar 8) merupakan tampilan layar utama yang terdiri dari menu master, menu transaksi dan menu report.

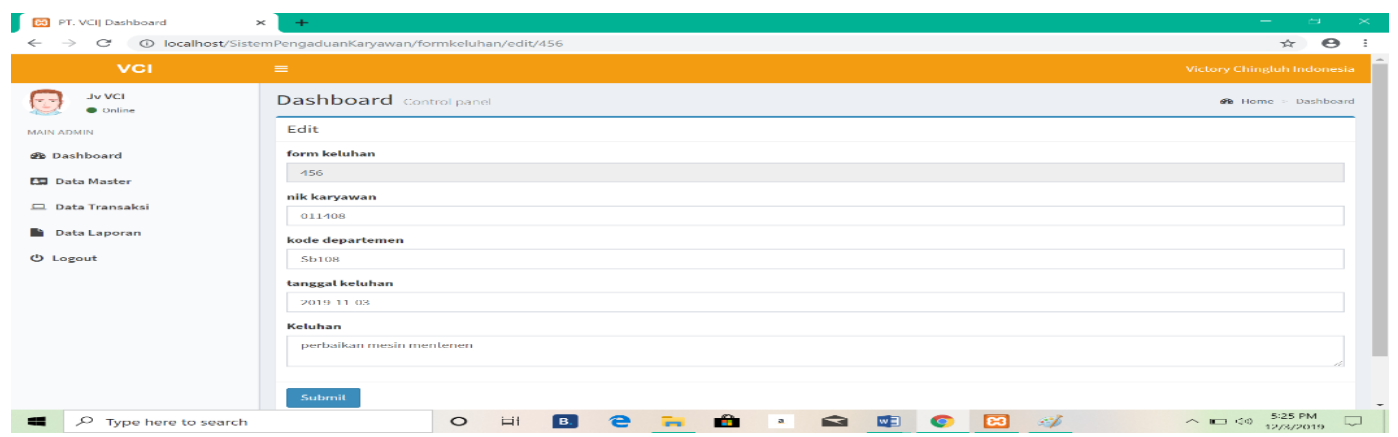

Gambar 9. Tampilan Menu Edit data form keluhan

Terlihat pada tampilan layar diatas (gambar 9) merupakan tampilan layar utama yang terdiri dari menu master, menu transaksi dan menu report, dimana menu transaksi memiliki sub menu Form keluhan dan terdapat di dalamnya salah satu yaitu Edit form keluhan. 


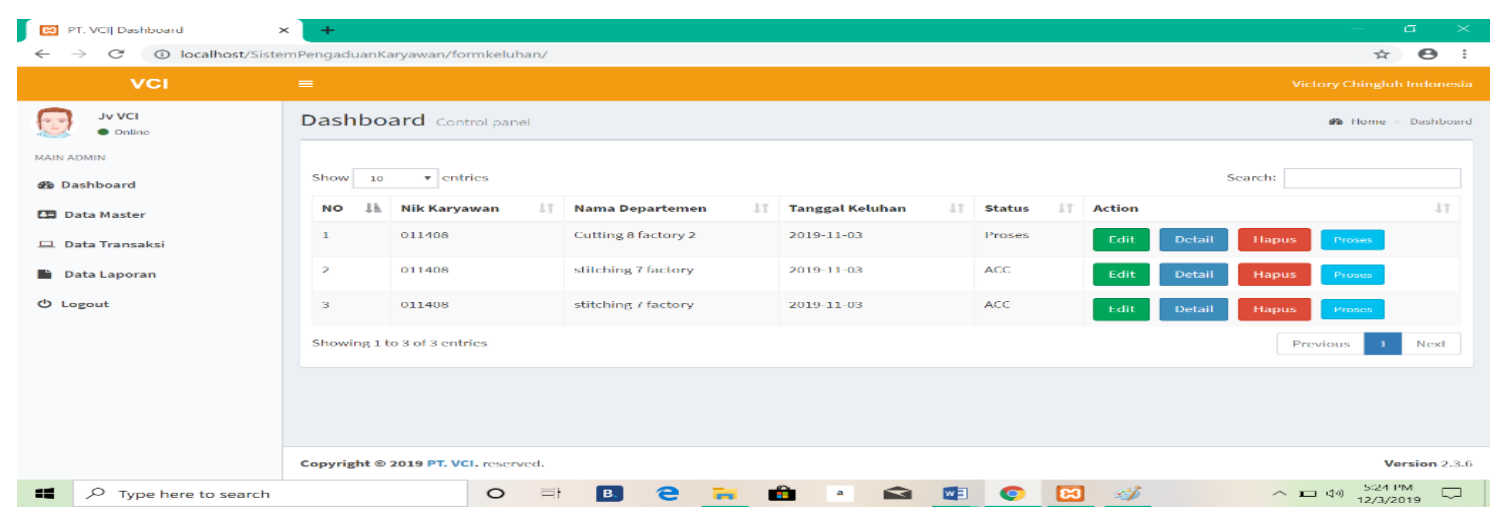

Gambar 10. TampilanForm keluhan yang masuk

Terlihat pada tampilan layar diatas (gambar 10) merupakan tampilan layar utama yang terdiri dari menu master, menu transaksi dan menu report, dimana menu memiliki sub menu karyawan, departemen, form keluhan dan kepuasan karayawan, rekap keluhan, dan transaksi memiliki field yang akan memberikan informasi keluhan yang masuk.

\subsection{Query Penciptaan Informasi}

\section{Query Function Tambah Aksi:}

function tambah_aksi ()\{

\$kd_dept $=$ \$this->input->post('kd_dept');

\$nik_kar $=$ \$this->input->post('nik_kar');

\$tgl_kel = \$this->input->post('tgl_kel');

$\$$ keluhan $=\$$ this- $>$ input->post('keluhan');

$\$$ status $=\$$ this->input->post('status');

$\$$ data $=$ array

\{

'nik_kar' => \$nik_kar,

'kd_dept' $=>$ \$kd_dept,

'tgl_kel' => \$tgl_kel,

'keluhan' => \$keluhan,

'status' => \$status

\};

\$this->m_formkeluhan->input_data(\$data,'formkeluhan');

\$this->session->set_flashdata('msg','data berhasil di terkirim');

redirect('formkeluhan/tambah'); \}

\section{Query Function Edit:}

function edit $(\$ i d)\{$

\$where = array ('no_formkel' $=>$ \$id);

\$data['formkeluhan'] $=\$$ this->m_formkeluhan $>$ edit_data(\$where,'formkeluhan')>result();

\$this->load->view('header'); \$this->load->view('edit_formkeluhan',\$data);

\$this->load->view('footer');

\section{Query Function Update:}

function update1() 


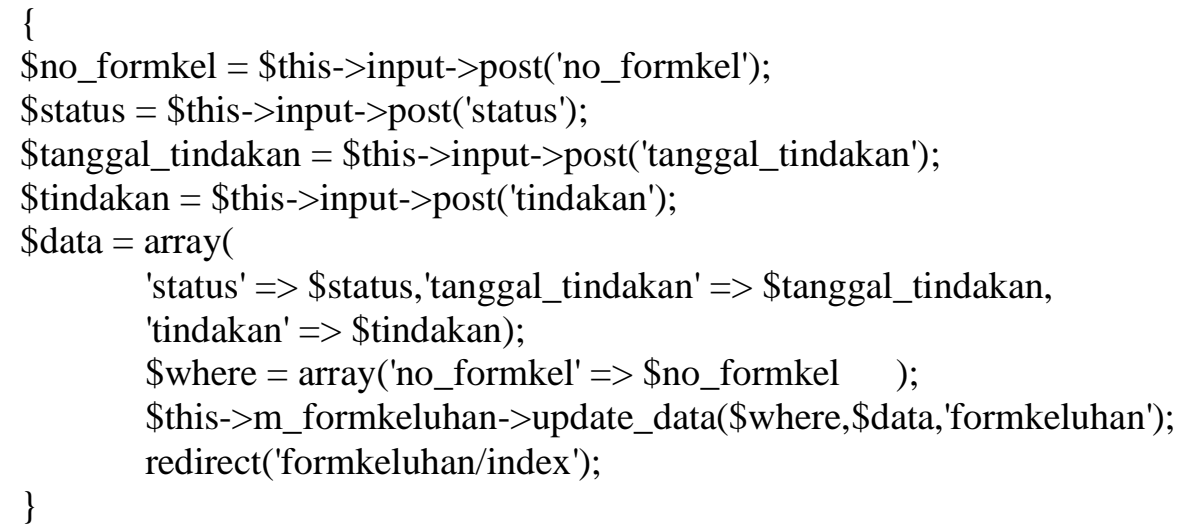

\section{KESIMPULAN}

Berdasarkan hasil analisa dan yang dilakukan, disimpulkan bahwa proses pengaduan karyawan menggunakan form sangatlah manual, yang menyebabkan pemborosan biaya selain itu juga proses menjadi tidak efektif dan efisien. Hal ini terlihat dari lamanya waktu yang dibutuhkan, mulai dari proses penginputan data sampai dengan pembuatan laporan penyelesaian tindakan, selain itu juga menyebabkan tingkat keakuratan yang rendah, karena masih terdapat beberapa kesalahan.Untuk mengatasi permasalahan diatas, model sistem pengaduan karyawan mampu mengukur kepuasan pelayanan perusahaan terhadap karyawan, sehingga dapat di jadikan dasar keputusan untuk menanganan keluhan dengan tepat, selain itu juga mampu menciptakan laporan penyelesaian tindakan dan rekapan penyelesaian tindakan dengan akurat menggunakan beberapa metode analisa dan perancangan yang dilakukan, dan pada akhirnya secara tidak langsung dapat meningkatkan kinerja perusahaan.

\section{SARAN}

Berdasarkan hasil penelitian dan Analisa penulis mengajukan beberapa saran yang dapat dimasukan untuk meningkatkan kualitas sistem, yaitu sebagai berikut:

1. Sistem yang dibuat ini secara intranet yang hanya dapat diakses melalui komputer dilingkungan perusahaan, kedepannya bisa di kembangkan dengan dibuat secara online

2. Untuk dapat memaksimalkan penggunaan sistem ini perlu diadakanya pelatihan kepada seluruh karyawan agar dapat diakses oleh seluruh karyawan dan dapat digunakan dengan maksimal.

Demikian, saran yang penulis bisa sampaikan agar sekiranya perusahaan bisa mewujudkan beberapa poin yang baik demi kelancaran dan peningkatan service yang di berikan.

\section{DAFTAR PUSTAKA}

[1] Junaidi, J., Effendy, M. Y., \& Hartono, H. (2015). REKAYASA MODEL APLIKASI SISTEM PRODUCT KNOWLADGE UNTUK MENDUKUNG PENGAMBILAN KEPUTUSAN DALAM MENENTUKAN KINERJA KARYAWAN. CERITA Journal, 1(1), 46-55.

[2] Martono, A., \& Junaidi, D. Y. IMULATION GAME BASED ON JARIMAGIC METHOD TO CALCULATE MORE QUICKLY FOR ELEMENTARY STUDENTS. 
[3] Junaidi, J., Cholisoh, N., \& Hasanah, N. (2018). Rancang Bangun Sistem Manajemen Aset IT Untuk Pencatatan History Maintenance Sebagai Pendukung Keputusan. SENSI Journal, 4(2), 220-231

[4] N. Cholisoh, H. Henderi, and S. Khodijah, "RANCANG BANGUN SISTEM ADMINISTRASI PERIZINAN KURSUS UNTUK MENINGKATKAN PELAYANAN MASYARAKAT PADA PUSAT PEMERINTAHAN", Journal CERITA, vol. 5, no. 2, pp. 189-201, Aug. 2019.

[5] Junaidi, J., Sutrisno, S., \& Janah, K. (2019). MODEL APLIKASI PURCHASING SYSTEM UNTUK MONITORING STOK DALAM MENGURANGI TINGKAT KERUGIAN. SENSI Journal, 5(1), 86-98.

[6] M. Subekti, Warnars Junaidi, H.L.H.S., Y. Heryadi, "The 3 steps of best data warehouse model design with leaning implementation for sales transaction in franchise restaurant", Cybernetics and Computational Intelligence (CyberneticsCom) 2017 IEEE International Conference on, 20-22 Nov 2017.

[7] J. Junaidi A. Husain, and J. Manda, "RANCANG BANGUN SISTEM INFORMASI SIMPAN PINJAM SEBAGAI MONITORING UNIT KERJA UNTUK MENGUKUR KINERJA ANGSURAN PEMBAYARAN", ICIT Journal, vol. 5, no. 2, pp. 213-224, Aug. 2019.

[8] J. Junaidi, A. Julianto, N. Anwar, S. Safrizal, H.L.H.S. Warnars, K. Hashimoto, "Perfecting a Video Game with Game Metrics", Telkomnika, vol. 16, no. 3, pp. 13241331, June 2018 